\title{
Climate change-that is not real! A comparative analysis of climate-sceptic think tanks in the USA and Germany
}

\author{
Timo Busch $^{1}$ (D) $\cdot$ Lena Judick ${ }^{1}$
}

Received: 8 May 2020 / Accepted: 5 January 2021 / Published online: 24 January 2021

(C) The Author(s) 2021

\begin{abstract}
The science is clear: climate change is real. In 2015, 195 countries adopted the global climate deal in Paris. Nonetheless, numerous well-organized conservative think tanks (CTTs) deny that climate change is happening. We ask what kind of counterclaims are used by climate-sceptic CTTs and to what extent these counterclaims change over time. We analyse about 2500 blog articles from prominent CTTs in the USA and Germany between 2008 and 2016. Our results show that sceptical arguments about climate policy and science dominate the countermovement. At the same time, we detect that the prevalence of counterclaims is CTT-specific and that US think tanks show a greater variability compared to their German counterparts. In a surprising outcome, we find that the Paris Agreement did not affect the climate denial movement. Based on these insights, we discuss our contributions to social movement research in the climate change denial context and derive conclusions for pro-climate campaigns.
\end{abstract}

Keywords Climate change scepticism $\cdot$ Conservative think tanks $\cdot$ Social movements

\section{Introduction}

The Paris Agreement represents a milestone in international policies to combat climate change. At the same time, there is a robust countermovement of climate sceptics that continues to try and undermine and question effective climate change efforts. In addition, we see several challenges from geopolitical shifts to the influence of lobby groups and major corporations for climate change negotiations, especially during the yearly United Nations Climate Change Conference (Banerjee 2012). Climate scepticism that is prominently declared has a substantial impact on the way climate change is perceived by the public (McCright et al. 2016), and

Timo Busch

Timo.Busch@uni-hamburg.de

1 Universitat Hamburg, Hamburg, Germany 
countermovement advocacy groups, such as conservative think tanks (CTTs), are identified as key players in the climate change debate (Oreskes and Conway 2011; Brulle et al. 2012).

A countermovement can be either progressive or reactionary - its critical characteristic is a dependence on and a reaction to an initiating social movement (Meyer and Staggenborg 1996). The nascent literature on CTTs indicates that in order to understand the nature of lasting climate change scepticism, it is essential to analyse and understand the counterclaims used by climate-sceptic CTTs (Cann 2015). At various levels, CTTs question facts about climate change and try to hamper climate policy using their counterclaims. By denying the scientific findings and undermining the policy proposals of their opponents, CTTs aim to neutralize their opponents' claims in an attempt to convince the public, as well as indecisive politicians, to follow their viewpoints instead.

While there is empirical evidence that counterclaims change in general (Cann and Raymond 2018) and that the climate sceptical discourse is not static (Schmid-Petri et al. 2017), only a few studies have systematically analysed the sceptical counterclaims of various CTTs in detail over time. In their content analysis, McCright and Dunlap (2000) deliver the most comprehensive survey of CTT counterclaims about climate change by analysing 224 documents from 1990 to 1997 . They find that the majority of the documents contain criticisms of the scientific evidence of global warming. Boussalis and Coan (2016) conducted a large text-mining of 16,000 documents from CTTs for the time frame 2008-2013, demonstrating as a main finding that these think tanks increased their discussions about the uncertainty of climate science. Two more recent studies, by Cann and Raymond (2018) as well as Cann (2015), focused on one American CTT, the Heartland Institute, and analysed documents confirming the results of previous research that there is a clear indication of a continued reliance on science framing. Both studies point out that CTTs are particularly reactive to the external environment: the volume of information produced by CTTs is affected by external events (such as the 2006 release of Al Gore's book and documentary film An Inconvenient Truth) and CTT counterclaims.

While existing studies focus on CTTs in the USA or in other individual countries, no comparative study has yet been conducted that analyses the CTT counterclaims in two different countries and how these change over time. In this article, we analyse the counterclaims of CTTs in Germany and the USA - two countries with different histories of climate change policy (van der Wurff 2009). The German government supported renewable energies quite early, e.g. with the Renewable Energy Sources Act coming into effect in 2000. Moreover, in recent years Germany has strengthened its ambitions to cut down $\mathrm{CO}_{2}$ emissions. On the other hand, in 2017 President Trump announced that the USA would withdraw from the Paris Agreement. We expect that these different approaches to climate policy affect the argumentation of climate-sceptic CTTs.

We seek to answer the following question: What kind of counterclaims are used by climate-sceptic CTTs in the USA and Germany, and to what extent do they differ and change over time? In order to answer this question, we provide an in-depth content analysis of four climate-sceptic conservative think tanks, analysing over 2500 documents from 2008 to 2016. A central finding is that-although the framing over time is CTT-specific - the counterclaims in the categories "Political Ideology" and "Science" continue to play a dominant role for all four CTTs. Furthermore, we find the surprising outcome that the relevance of arguments did not change after the Paris Agreement. And finally, the paper illustrates that there is greater variability in the reasoning of US CTTs compared to German CTTs. 
This paper contributes to the literature on social movement research in the climate change denial context. By developing a deeper understanding of organized climate scepticism, and by investigating the differences between German and US CTTs, we respond to the call for indepth analyses of think tanks and their counterclaims across nations and over time in order to understand the climate-sceptic debate and its actors more thoroughly (Hoffman 2011; Dunlap and McCright 2015; Boussalis and Coan 2016). Furthermore, our results illustrate how organized climate change denial as a social movement has evolved over time and demonstrate which dominant counterclaims prevail. Having a better understanding of the development of CTT misinformation is necessary to enable effective and targeted pro-climate awareness campaigns in response to the efforts of the climate denial movement.

In the following sections, we start by examining previous research on the climate change countermovement and related conservative think tanks. Next, we describe our research approach, illustrating our data collection and data analysis, and then report our findings. Finally, we conclude by proposing further steps going forward, discussing theoretical and policy implications of future research.

\section{Theoretical background and related literature}

\subsection{Social movements and countermovements}

Research on social movements has grown impressively since the 1990s (Rucht 1990; Klandermans and Staggenborg 2002). The peace movement, anti-nuclear energy protests, the gay rights and women's rights movements, student protests, environmental movements, as well as fundamentalist religious and nationalist movements, among others, have increasingly came to the attention of sociologists, political scientists, and historians who have studied the emergence and development of these movements under the umbrella of social movement theory (Johnston et al. 1994; McAdam 1996). Social movement organizations are seen as "important sponsors in the framing process" (Gamson and Modigliani 1989, p. 7). As social movement organizations sought to influence interpretations of reality among various audiences or receivers, focussing on the utilized frames became one of the most popular approaches to analyse reality construction and the rhetorical processes of different movements (Benford 1997).

While a social movement can initiate and stimulate a certain process, it can also trigger a subsequent movement whose set of opinions and beliefs is opposed to the goals and demands of the initial movement - a countermovement (McCarthy and Zald 2015). Although countermovement analysis remains a rather under-researched field of study, several scholars have laid the foundations to understand the emergence and development of these opposition movements (Meyer and Staggenborg 1996; Noakes and Johnston 2005). Notably, such movements have been very effective - in practice - at undermining progressive movements' frames by deeming such frames illegitimate (Noakes and Johnston 2005). This denying effort clearly seeks to “rebut, undermine, or neutralize a person's or group's myths, versions of reality or interpretive framework" (Benford 1987, p. 75).

In the $1980 \mathrm{~s}$, countermovements were merely seen as reactionary protest movements against the social change being promoted by an initial movement. This view was later challenged by a more dynamic approach to how movements engage and relate with each other. Thus, a countermovement can be either progressive or reactionary-its critical 
characteristic is its dependence on and reaction to an initiating social movement (Meyer and Staggenborg 1996).

By advocating and lobbying for change, by attacking established interests, and by mobilizing symbols and raising awareness of the costs to others, the initial movement identifies the grievances and creates opportunities for individuals or organizations to define the goals and issues of the countermovement (Zald and Useem 1987). As movements and countermovements compete with each other, framing processes are also directly affected by these struggles (Noakes and Johnston 2005). The climate change discourse offers an interesting case for studying these dynamics in detail.

\subsection{Climate-sceptic conservative think tanks}

Within public climate change debates, CTTs play an important role in spreading the notion of climate change scepticism. Studies have examined the ways that different stakeholders, such as large corporations or professional engineers/geoscientists, use framing tactics in order to illegitimate the scientific consensus about anthropogenic global warming (Lefsrud and Meyer 2012; MacKay and Munro 2012; Levy and Kolk 2002).

Functioning as an "apparatus for the incubation and diffusion of conservative ideas" (Dunlap and McCright 2015, p. 304), CTTs have played a leading role in the so-called denial machine (Begley 2007). Dunlap (2013) describes this "denial machine" as a "loose coalition" driven by corporate interests, mostly those of fossil fuel companies. Heavily funded by conservative foundations (Brulle 2014), this coalition mainly consists of a large number of think tanks (McCright and Dunlap 2000), advocacy groups, and trade associations attempting to influence the climate change discussion by setting up specific campaigns (Oreskes and Conway 2011). "CTTs quickly developed into a powerful political force widely recognized to have shifted American politics significantly rightward" (Dunlap and McCright 2015, p. 304).

These well-funded conservative think tanks have been studied and analysed at several points (e.g. Stefanic and Delgado 1996; Dunlap and McCright 2010; Dunlap and McCright 2015). Over time, their importance has been increasingly recognized, and research on their tactics and arguments has been published. CTTs have continued to depict climate science as flawed and have continued to issue warnings about the severe economic consequences of climate change policies. Additionally, new areas of climate misinformation seem to have emerged. CTTs have increasingly focused on the causes of climate change, suggesting that it is a natural phenomenon with regular systemic cycles, and rejecting the idea that humans have played a significant role in contributing to it. Furthermore, renewable energy sources have "almost always [been] presented as inadequate solutions on their own" (Boussalis and Coan 2016, p. 94), particularly in contrast to fossil fuels.

\subsection{Counterclaims about climate change}

A great deal of research on the prevalence of climate change scepticism has been accomplished in the areas of communication, journalism, and media (e.g. Trumbo 1996; Shehata and Hopmann 2012; Elsasser and Dunlap 2013; Kaiser and Rhomberg 2016; Schmid-Petri and Arlt 2016; Schmid-Petri et al. 2017). Additionally, some authors have examined in detail the content of contrarian information, and a few of those have had a particular focus on CTTs (Boussalis and Coan 2016; Cann 2015; Cann and Raymond 2018, Jacques et al. 2008; McCright and Dunlap 2000). Elsasser and Dunlap (2013), for example, have emphasized 
the contrarian discourse as a whole, such as investigating which think tanks employed a list of sceptical arguments to categorize over 200 relevant op-eds.

McCright and Dunlap (2000) analysed 224 publications by 14 CTTs in a single year survey. Also focusing on 1 year, Cann (2015) investigated documents from the Heartland Institute. Cann and Raymond (2018) also analysed the publications of one CTT over the course of 1 year. By their nature, these studies offer little information about the evolution of CTTs' counterclaims. Boussalis and Coan (2016) provided a first systematic analysis of conservative think tanks over time and demonstrated that both policy and science discussions remain stable during their observed period. They stress that in-depth analyses of CTTs' arguments are lacking, especially in order to determine the prevalence of both new and past counterclaims. Hoffman (2011) created a comprehensive analysis of the contrarian movement in 2010. This study was based on one CTT, the Heartland Institute, and focused on a single year. We therefore seek to expand upon these efforts by comparing four CTTs from two countries over a multiyear period.

\section{Research design and methods}

\subsection{Research context}

We conduct a qualitative content analysis of counterclaims deployed by four CTTs during the period between 2008 and 2016. We chose CTTS based in the USA and Germany because the two countries have advocated for different policy approaches in response to the challenges of climate change. The USA is well known for not ratifying the Kyoto Protocol (McCright and Dunlap 2003). The influence of CTTs on US climate policies has become more visible under President Trump, who has repeatedly deployed climate-sceptic arguments in public. Conversely, in 1991, Germany was the first country in the world to introduce a law promoting renewable energy. Since then, several further climate policies have been enacted, for example, a binding feed-in tariff for electricity from renewable energy sources.

Furthermore, surveys show that in 2016, 30\% of Americans did not believe that climate change is occurring at all and $48 \%$ did not believe that human activity is the main cause of global warming (Howe et al. 2017). By comparison, in Germany in 2016, 16\% of the population did not believe that the world's climate is changing, while up to $15 \%$ denied that human activity is the main cause of global warming (Steentjes et al. 2017).

American CTTs helped to spread the climate-sceptic debate internationally (Jacques et al. 2008). However, it remains unclear whether CTTs in Germany have adapted American CTT counterframing to local conditions, or if German CTTs have merely imitated their US counterparts (Kaiser and Rhomberg 2016; Häussler et al. 2017).

\subsection{Empirical design and methods}

In the USA, we analysed the counterclaims of the Heritage Foundation and the Cato Institute. In Germany, we chose the Berlin-based Liberales Institut, which is affiliated with the liberal foundation Friedrich-Naumann-Stiftung für die Freiheit (The Friedrich Naumann Foundation for Freedom) and the Europäisches Institut für Klima und Energie (EIKE, European Institute for Climate and Energy). We conducted a systematic search of the different weblogs from the think tanks regarding content about climate change and global warming, such as articles or 
comments on policy and science, the Intergovernmental Panel on Climate Change (IPCC), and COP events. The sampling focused on blog articles that were published between 2008 and 2016. We chose this specific time period because it begins with the "Climategate" phase, which brought a "series of events that galvanized the climate denier movement" (Hoffman 2011, p. 4). The period ends 1 year after agreement on the Paris Agreement in 2015, which symbolizes a historic milestone for climate change. As such, the chosen time frame allows us to investigate the extent to which the Paris Agreement resulted in a change of argumentation.

For the German think tank EIKE, which almost exclusively publishes content on climate change topics, we saved every blog post from January 2008 to December 2016 as a first step. EIKE also sent out newsletters that were published on its blog and so we also included these. This led to 5103 documents in total that we reduced to 833 documents for the analysis applying systematic sampling.

To gather relevant articles from the Liberales Institut's blog, all posts categorized by the tags "Environmental and Climate policy" and "Energy policy" were downloaded prior to manually excluding the redundant and irrelevant articles that did not cover climate change or only covered it in passing. As the blog only published material in the above-mentioned categories between November 2009 and February 2015, the evaluation of the Liberales Institut's weblog is limited to this period.

For the Cato Institute, all blog posts sorted within the category "Energy and Environment" on its weblog "Cato at Liberty", which dealt with climate change issues, were included in our qualitative analysis. The Heritage Foundation's weblog "The Daily Signal” lacks categories to identify relevant articles, so two different search strings with "Global Warming" and "Climate Change" were conducted from the period January 2008 to December 2016.

The search outcome was initially checked and suitable content was saved. The results were manually controlled for redundancies (Table 1).

\subsection{Data analysis}

Our sample included blog articles from the four CTTs between January 2008 and December 2016. Images and videos were not analysed. We used Hoffman's (2011) seven categories (Science, Risk, Technology, Economy, Religion/Values, Political Ideology, and National Security) as well as the proposed counterclaims identified by McCright and Dunlap (2000) as starting point for our codebook. The codebook consists of several counterclaims that are

Table 1 Sample of blog posts per CTT by year and in total

\begin{tabular}{lllll}
\hline \multicolumn{2}{l}{ Conservative think tank (CTT) } & & \\
\hline Year & Lib. Institut & EIKE & Cato Institute & Heritage Foundation \\
\hline 2008 & $/$ & 64 & 32 & 125 \\
2009 & 17 & 96 & 50 & 98 \\
2010 & 170 & 97 & 26 & 102 \\
2011 & 151 & 96 & 8 & 30 \\
2012 & 106 & 96 & 23 & 28 \\
2013 & 90 & 96 & 76 & 34 \\
2014 & 71 & 96 & 83 & 90 \\
2015 & 9 & 96 & 100 & 51 \\
2016 & $/$ & 96 & 83 & 80 \\
In total & $\mathbf{6 1 4}$ & $\mathbf{8 3 3}$ & $\mathbf{4 8 1}$ & $\mathbf{6 3 8}$ \\
\hline
\end{tabular}


each linked to one of the above-mentioned categories. To explain each counterclaim, several examples are given to illustrate their meaning.

In a second step, we adjusted the preliminary codebook based on the screening of the CTT documents and our literature review (see Table 2 for the final codebook). A first major change was using two different counterclaims in place of the single counterclaim Scientific Uncertainty, namely, distinguishing between Trend and Process in terms of Scientific Uncertainty. Reflecting current research on different types of climate scepticism, we reflect two different strategies used to manufacture uncertainty about climate science. One strategy uses claims that climate change is not occurring at all, that the earth is in fact cooling, or that warming has stopped; these claims are subsumed under the counterclaim Scientific Uncertainty (Trend). Arguments that attack climate science (and its underlying scientific and organizational processes) in general, by claiming, for example, that the IPCC process was "flawed" and that climate models are wrong, are listed under Scientific Uncertainty (Process). This was further complemented by having recourse on the so-called "process scepticism" as identified by van Rensburg (2015), which subsumes criticism of the scientific, bureaucratic, and political processes behind climate science and aims to attack the integrity of climate research. The intention was to find out whether CTTs are still denying outright that climate change is occurring at all, or whether they have shifted their strategies in order to admit the reality of global warming, and instead dispute that human activity is its primary cause.

The second major change was the inclusion of a counterclaim in the category Risk, namely, one that argues that adaptation is more appropriate than mitigation. This counterclaim was recognized during the content analysis and constructed inductively as CTTs argued for adaptation strategies instead of $\mathrm{CO}_{2}$ mitigation. This is because if climate change is real, then only adaptation strategies will work. Mitigation measures were presented by CTTs as costly, inefficient, or as coming too late to have the desired outcome.

After finalizing the codebook, the coding procedure started. The coding was done by three researchers with extensive training in qualitative research. Each of the researchers read the respective document sentence-by-sentence, highlighting whether a sentence (or more) in the text refers to one of the counterclaims. To ensure intercoder reliability, as a first step, the codebook was pre-tested on 30 blog articles resulting in a Krippendorff's alpha score of .603, which indicates substantial reliability. As our unit of meaning, we decided to code phrases/arguments in which the legitimacy of an anthropogenic global warming was challenged. This could either be one or two sentences or a whole passage if the passage accounts for the same argumentation. This pre-test phase was also used to ensure that all coders have the same sense for the codes and that possible conflicts could be anticipated. During this pre-test, we also checked whether further adjustments to the codebook were necessary. This led to further minor changes in the formulation of the given examples. Table 2 shows the full codebook illustrating all counterclaims.

In the final coding, each of the blog articles was coded using the final codebook. The three coders completed the coding manually, supported by the computer-assisted qualitative data analysis package MAXQDA. During the coding process, the coders met regularly to discuss open questions and to ensure that the coding was proceeding under the same consistent standards. They agreed upon coding rules, such as deciding that citations in the text or single words would not be coded at all. Each blog article was coded sentence-by-sentence. If 
Table 2 Detailed codebook

Category Counterclaim Code Examples

I. Science

Scientific Uncertainty (Trend)

Scientific Uncertainty (Process)

\section{Causes of Climate Change}

More Research Needed Scientists' Agenda

II. Risk

Precautionary Principle

Physical Risks

Public Health Risks

Externalities
101 - There is no (post-industrial) warming (e.g. because current weather proves that: ice is not melting; sea level rise is exaggerated; wrong measurement because of "urban heat island effect"; MSU data shows no or only weak warming trend)

- The world is actually cooling

- Global warming has stopped in the twenty-first century despite emissions growing

102 - The IPCC process for determining the scientific evidence is flawed (e.g. peer review by "buddies", usual quality standards are ignored)

- Scientific evidence is highly uncertain (e.g. climate models are wrong or inadequate)

- There is no consensus in the scientific community

103 - Climate change is not caused by humans or is caused by natural forces (e.g. climate has changed before; $\mathrm{CO}_{2}$ is released from the oceans)

- Claims that human activities are changing the climate are exaggerated

- Climate change is caused by extra-terrestrial influence (e.g. by the sun/solar radiation, cosmic rays, earth axis movement, volcanism)

- Greenhouse effect does not exist and/or $\mathrm{CO}_{2}$ not responsible for global warming (e.g. $\mathrm{CO}_{2}$ is not a pollutant; calculation of radiation is correct, but response of climate system is weaker then thought; absorption bands of $\mathrm{CO}_{2}$ are already saturated; climate sensitivity is low)

104 - More research on climate change is necessary

105 - Climate change is a hoax, a myth

- Scientists calling for action are ideologically motivated

- Scientists are using evidence selectively and/or modified data to foster their cause (e.g. Climategate)

- Scientists are exaggerating their findings

- Scientists are ideologically and/or economically motivated (e.g. to get more grant money for their research)

- Scientists oppress critics

- Scientists use scare tactics to convince the public (they are "alarmists" or "fearmongers")

201 - We have time to wait for more scientific clarity before actions are needed

- Risk is not great enough to act, since there are questions about the evidence on climate change

- No need to act now

- It is too early to say whether climate change is really a problem 202 - Physical risks are exaggerated, hyped, and overplayed, or only apply to others (e.g. droughts, hurricanes, melting ice, species extinction, biodiversity loss)

- It is no problem because nature (animals and plants) will adapt

203 - Health or social risks are exaggerated, hyped, and overplayed, or only apply to others (e.g. diseases, public health disasters)

204 - Climate change has positive externalities (e.g. longer growing seasons, milder winters, better quality of life)

- Addressing climate change will not affect our ability to deal with social or health risks 
Table 2 (continued)

Category Counterclaim Code Examples

Adaptation Better than Mitigation

III. Technology

Type of Technology

(Picking Winners)

\section{Economy}

Cost-benefit

Economic Investment

(Jobs and Economy)

Economics of Energy

Discounting the Future

\section{Religion/Values}

Religion and Science
- Addressing climate change will cause negative externalities (e.g. poorer quality of life; other problems are not being dealt with; $\mathrm{CO}_{2}$ limits/climate measures will hurt the poor; destruction of nature due to renewable energy production; development opportunities of developing countries are endangered by climate measures) $\rightarrow$ unintended consequences

205 - There will not be bad consequences with adaptation

- In contrast to costly and inefficient mitigation strategies (e.g. cap and trade), adaptation works (e.g. construction of higher dykes, changes of infrastructure)

-We should cultivate new agricultural products, new breeds, new cultivation methods

- It is already too late to do anything about climate change, so better to adapt

301 - Advocating for technology as solution for climate change (e.g. CCS, geo-engineering)

- Championing tech-ready nuclear power as technological solution

- Dismisses renewables as a viable energy solution (compared to coal, nuclear, etc.)

- Champions a fuel mix but favours nuclear or gas

- Demanding openness for technology ("Technologieoffenheit") to solve climate change

- Hydraulic fracturing ("fracking") is better for the climate than renewables

401 - Cost-benefit analyses account for relevant economic variables and social/environmental externalities when evaluating climate change policy options

- Supporting commensuration of natural resources (it is ok to monetize natural resources) (Only code if it is about using earth's physical resources-NOT carbon or cap and trade)

402 - Long-term costs of addressing climate change will outweigh long-term benefits

- Economic costs of not addressing climate change will not be high

- Lose-lose scenario: short-term costs outweigh benefits; GHG control will hurt economy, jobs will be lost to overseas workers

- Citizens will have to pay (higher taxes, higher prices)

- There will be no "green jobs" boom

- Opportunity costs are too high (e.g. investments in climate measures are inefficient; money that was spent for climate mitigation will not be used in other important areas)

403 - Investing in renewables is not profitable or feasible now (and will not be in the future)

- Investing in nuclear, coal, or geo-engineering is profitable and feasible now or will be in the future

- Renewables and/or energy efficiency measures will not reduce climate gases (e.g. because of rebound effects)

- Renewable subsidies will lead to the renaissance of coal and push gas out

- The combination of cap and trade and renewable subsidies does not work

404 - Places high discount rates on future generations (e.g. they will be wealthier; people today do not value tomorrow as much; we cannot speak in the name of future generations)

501 - Scientific reason is hostile to religions and faith 
Table 2 (continued)

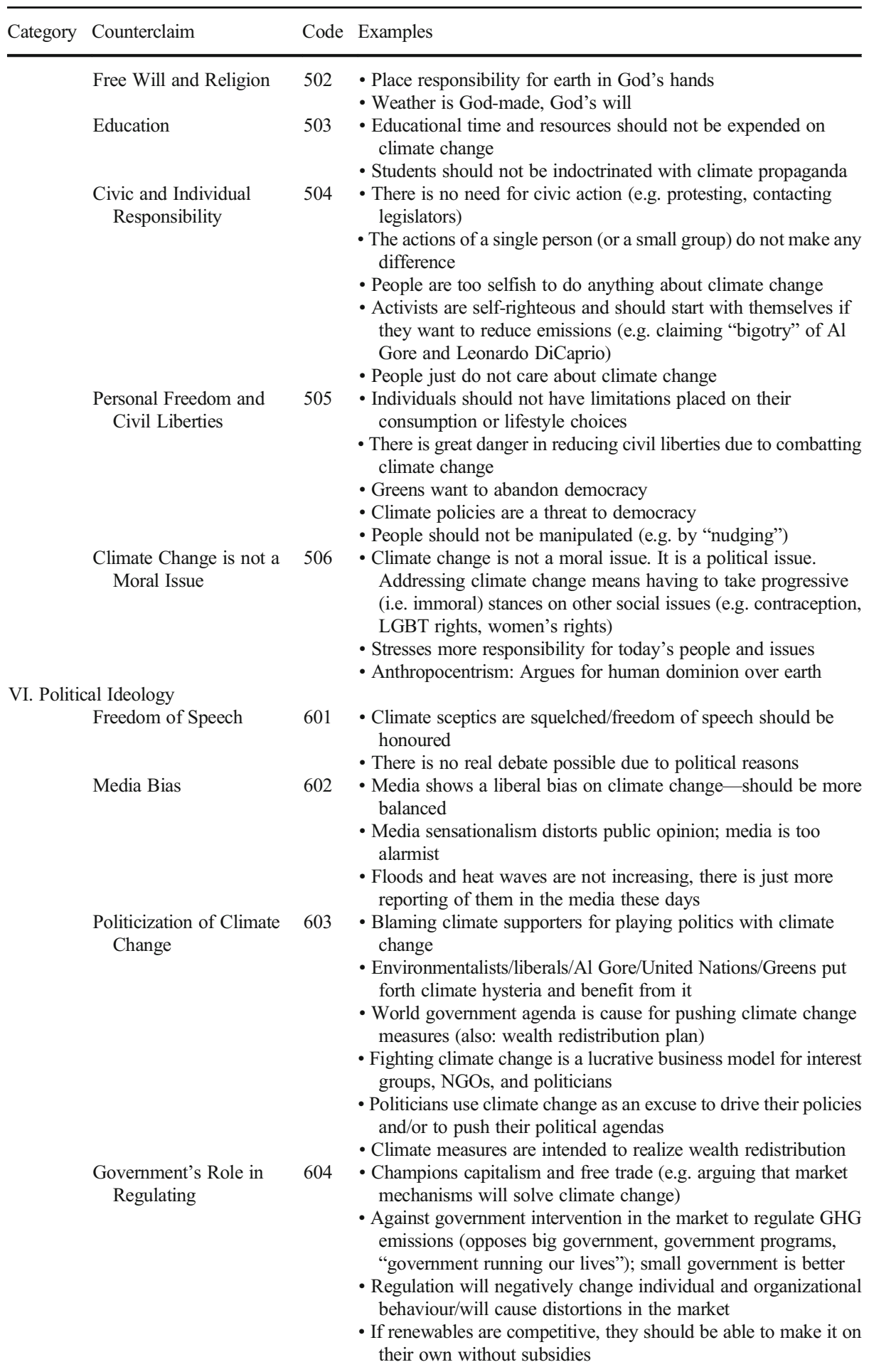


Table 2 (continued)

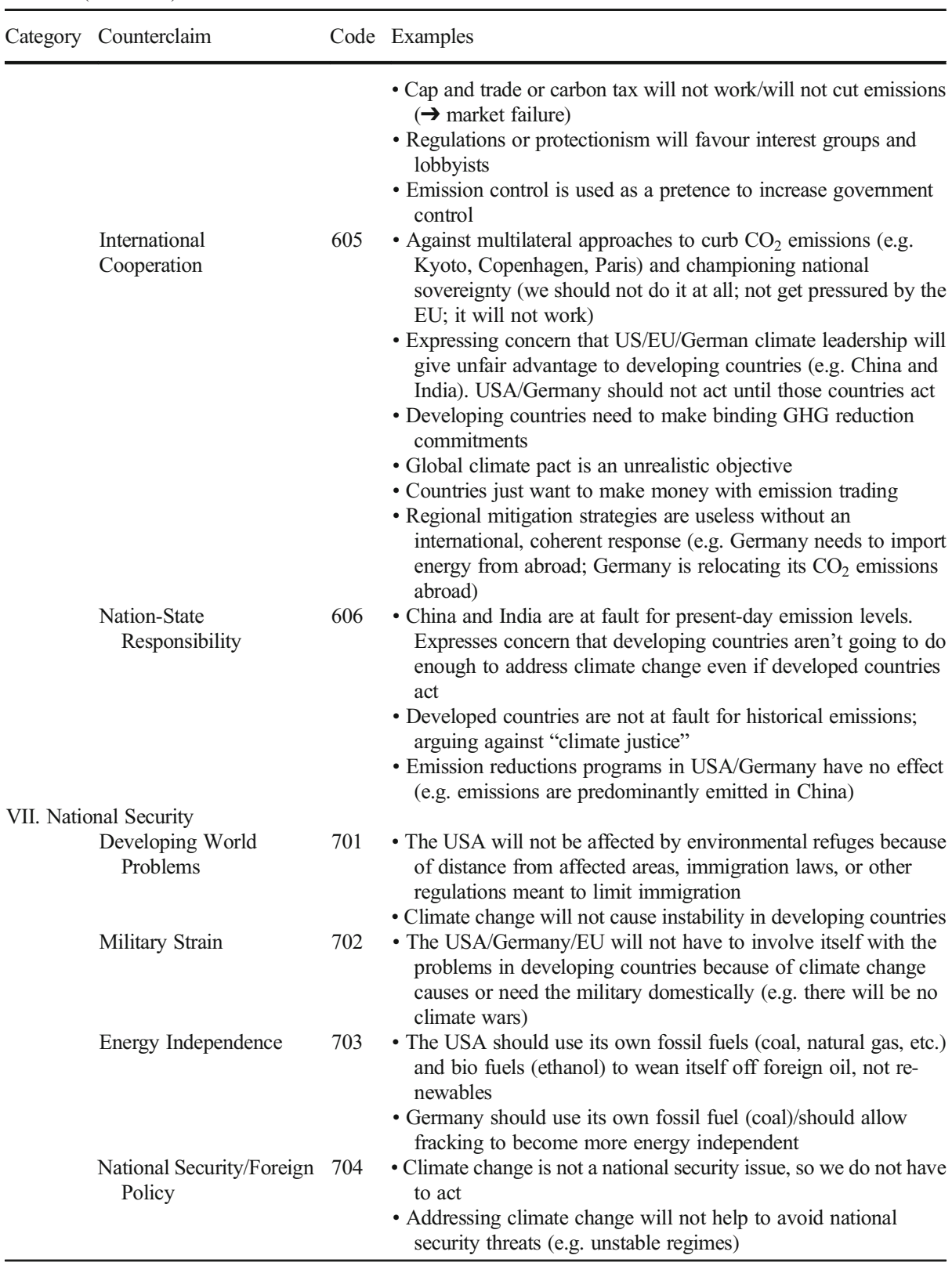

sentences expressed different counterclaims, each newly appearing counterclaim per blog article was coded. If a coder was not sure whether a special part of the text would belong to one of the counterclaims, he/she discussed this with the others. During these meetings, conflicts were also resolved. This ensured that our coding was consistent and accurate at all times. At the end of the coding, we used several MAXQDA analyses tools to illustrate our results and to compare the results for each CTT. 


\section{Results}

\subsection{Findings for EIKE}

EIKE is a central actor within the German climate change denial movement. A unique feature of EIKE as compared to the other three analysed CTTs is that it has been concentrating mostly on counterclaims in the category Science with smaller peaks in 2013 and 2015. This German think tank has denied that global warming is happening at all-it even suggests that global warming stopped in 1998 when the climate began cooling again. Carbon dioxide $\left(\mathrm{CO}_{2}\right)$ that was emitted by humans is depicted by EIKE as "harmless" and as only having a "marginal effect" on the climate. According to EIKE, the main drivers behind climatic changes are actually "natural"- solar cycles, cosmic rays, or cloud formations. An EIKE blog states that the climate sensitivity would be so marginal that:

[...] even if all available fossil fuels are burned completely, it would cause an increase of only 1 degree Celsius. Furthermore, there is no doubt that the measured increase of $\mathrm{CO}_{2}$ up to $0,038 \%$ is the result of warming, and not its cause [...] The regularly observed heating and cooling phases in earth's history can be attributed to natural causes [...]

(Own translation; EIKE, 5 January 2011)

EIKE regularly denied that there is a scientific consensus among (climate) scientists - e.g. by referring to a petition that circulated in 1999 in which any scientific evidence for global warming was denied (the so-called Oregon Petition). Furthermore, EIKE constantly attacked the IPCC and its climate models, depicting the IPCC models as wrong because its projections could not be confirmed by reality. Specifically, EIKE regularly attacked the Potsdam Institute for Climate Impact Research (PIK), whose scientists are involved in the activities of the IPCC, for "sloppy" and unscientific work. Furthermore, EIKE picked up and publicized the "Climategate", since, from their perspective, it confirmed that all mainstream climate scientists are corrupt.

The second most important category after Science is Political Ideology, where certain counterclaims were deployed in a significant manner (with a peak in 2014). The Media Bias counterclaim and the Politicization of Climate Change counterclaim in particular were used frequently. According to EIKE, journalists are biased in their reporting and would even launch deliberate disinformation campaigns about climate change. For EIKE, the media was not only guilty of "ecological brainwashing" but also of being part of an "eco-industrial complex". The Politicization of Climate Change counterclaim aggregates several of EIKE's claims that the German media and German politicians were deeply involved in the green movement and therefore pushed climate mitigation policy. In their opinion, environmentalists use global warming to exert pressure on companies and the capitalist lifestyle. Political-ideological goals (e.g. wealth redistribution, installation of a world government) were the driving force behind all that "climate alarmism". Furthermore, EIKE claimed that special interest groups ("climate lobbyists") and individuals like Al Gore would profit financially from climate change, while individuals and organizations that disclosed these procedures would be excluded from the public debate, making this claim by utilizing the Freedom of Speech frame.

The next two categories used by EIKE - Risk and Economy - were used far less frequently than the first two categories, and account for less than $10 \%$ of the detected counterclaims. In the Risk category, EIKE deployed the "classic" sceptical claims that there would be no connection between global warming and tornadoes, hurricanes, floods, or forest fires. On the 
contrary, EIKE blog posts suggested that the frequency and duration of extreme weather events would decrease in the twenty-first century.

In terms of the category Economy, according to EIKE, the real risk would actually be the negative impact of climate mitigation policies on the economy. EIKE warned that considerable economic damage would be caused in Germany by high energy costs and carbon taxes as companies would relocate to other countries to avoid these. This would lead directly to German deindustrialization and mass unemployment that would hit the poor the hardest. Furthermore, EIKE also attacked renewable energy technologies. The other three remaining categories represent $1-3 \%$ of the detected counterclaims during the whole time period observed and can therefore be neglected at this point.

\subsection{Findings for the Liberales Institut}

The Liberales Institut shows a more diversified picture than EIKE when looking into the prevalence of counterclaims used (Fig. 1). The first notable outcome of our analysis is the clear decrease of the Science category over the years we analysed (with the only peak in 2013). In contrast, the category Political Ideology had a constant rise and the category Economy gained importance during the years, although it had a significant drop in 2013. Unlike the EIKE, the Liberales Institut was not merely denying the existence of climate change but rather concentrated on attacking the processes behind climate science. Repeatedly, the scientific debate about climate change was framed as being controversial. Here, the German CTT doubted the scientific consensus in this field by referring to it only as "the supposed scientific consensus" or as a "pseudo-consensus". The IPCC in particular was criticized in this context.

The category Political Ideology was the most important field with continuously growing importance. The critique of the assumed Politicization of Climate Change often focused on responsible actors and their agendas, such as green politicians, lobbyists for renewable energy,
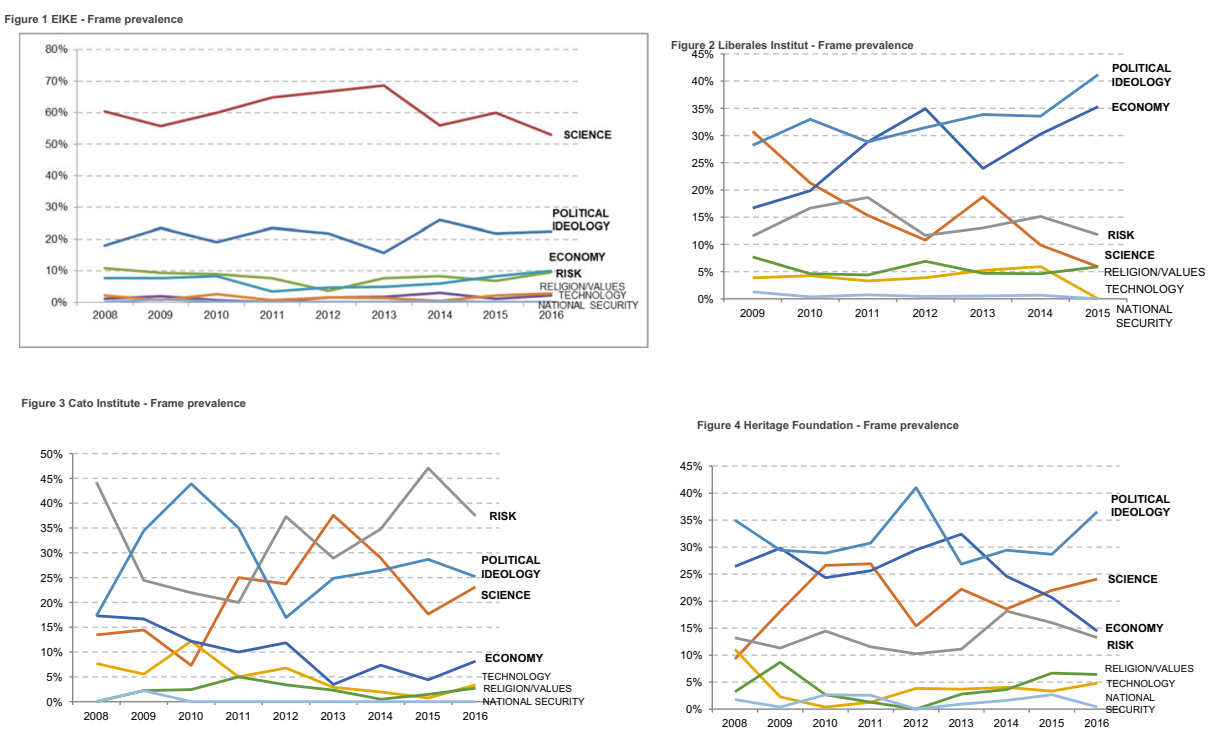

Fig. 1 Prevalence of counterclaims per CTT 
or eco-activists. According to the Liberales Institut, the German energy transition was a result of green ideology and lobbyism. Additionally, the CTT often framed green or ecological politics as being hypocritical and of hiding behind a "Save the World" approach, while the real truth would be that green politicians would only serve special interests. The CTT also accused Al Gore of "moneymaking" as he toured the world warning about the consequences of global warming while holding assets in companies that produce solar panels. Green activists as such and certain companies would work "hand in hand" to strengthen regulation and dismiss competition. Yet in the Liberales Institut's writings, the assumed hidden agenda or ideology behind that development remained vague.

Within the Economy category, this think tank criticized stronger climate policies as being harmful for economic growth and warned that they would put the free market at risk. The Economic Investment counterclaim and the Economics of Energy counterclaim were the most prevalent. While the first counterclaim generally described the devastating consequences of climate protection measures on the economy and the job market, the energy claim was deployed to attack renewable energies while highlighting the advantages of fossil fuels. While it was often claimed that climate change is a political tool to enforce wealth redistribution and tax increases, according to one of the Liberales Institut's blog articles, the fight against climate change and for renewable energies is:

[...] not about technique, it's about a new mode of society and its implementation or better said - enforcement. In the beginning of every totalitarian ideology, there is a dogma that may not be questioned and is guiding the way: the climate and the whole earth get destroyed by carbon dioxide introduced by humans into the atmosphere. This finding is irrefutable, the ever-lasting truth. (Own translation; Liberales Institut, 28 April 2010)

One focus of the Liberales Institut was to point out that "green investments" and emission reduction measures would do more harm than good. The think tank argued that rather than generating new jobs and income opportunities, the structural change towards an emission-free "green economy" would devalue production capital, knowledge, and skillsets. Furthermore, it criticized German and European Union climate policies: such regulations would undermine economic growth by increasing the cost of energy - while having no mitigation effect as $\mathrm{CO}_{2}$ emissions and jobs would just be relocated to countries without strict rules concerning climate protection.

Within the category Risk (between 10 and 20\% during the period, with peaks in 2011 and 2014), the risk of the negative effects of climate change were framed as high or at least exaggerated. The Liberales Institut utilizes the Externalities counterclaim by which it claimed that addressing climate change through mitigation strategies would cause several negative consequences - or even that climate change would have a positive outcome. The institute argued that other urgent social and ecological issues, like health problems or animal protection, were being ignored since climate change got top priority.

The category Religion/Values varies between 5 and $8 \%$ of the detected counterclaims during the period, with peaks in 2012 and 2015. Within this category, it is almost exclusively the Personal Freedom and Civil Liberties counterclaim that is used, and climate measures are portrayed as being restrictive to the personal freedom of citizens and endangering fundamental democratic rights. As the categories National Security and Technology only make up to $6 \%$ of the detected counterclaims during the whole period analysed, they can be neglected in the analysis. 


\subsection{Findings for the Cato Institute}

In the course of analysing the libertarian Cato Institute, we discovered that the category Economy did not play a major role in this think tank's communication. Instead, the focus of this CTT was on Risk, Political Ideology, and Science.

Within the Science category, there is quite some movement during the time period observed. It grew in importance from 2008 to 2013 (highest value in 2013, significant drop in 2010) and then dropped again until 2015 before it slowly rose until 2016. Cato does not deny that climate change is real, though it insists that the IPCC climate models are inaccurate. At least for its blog communications, this CTT shifted its focus away from outright climate denial to other forms of manufacturing uncertainty. Cato regularly claimed that the IPCC's climate models were too inaccurate to correctly project the rate of global warming. Attacks on the personal integrity of climate scientists (counterclaim: Scientists' Agenda) could also be found in nearly every 10th blog article. Altogether, the overall focus within the Science category was to frame the anthropogenic influence on the climate as existent but insignificant, while warming rates were presented as being not as bad as feared. This approach reflects a new framing strategy that Cato itself described quite openly as "lukewarming":

These days there is a legion of well-paid climate spin doctors. Their job is to keep the debate binary: either you believe climate change is real and dangerous or you're a denier who thinks it's a hoax. But there's a third possibility they refuse to acknowledge: that it's real but not dangerous. That's what I mean with lukewarming, and I think it's by far the most likely prognosis. (Cato at Liberty, 26 October 2016)

Reflecting this strategy, the category Risk was the most prevalent in Cato's blog (peaks in 2012 and 2015). Between 2012 and 2016 in particular, Cato argued that the risks posed by global warming were exaggerated for several reasons: ice caps and glaciers would be a lot more stable than predicted; there is no relationship between carbon dioxide emissions and extreme (weather) events like hurricanes, tornadoes, wild fires, and floods; and sea levels are not rising.

The Political Ideology category had a strong rise from 2008 to 2010 (from 17 to $44 \%$ in 2010) and lost importance after 2010 (highest value in 2010 and a low point in 2012). Cato criticizes governmental regulation with regard to combatting climate change as ineffective and harming the economy. Here, the Clean Power Plan from the Environmental Protection Agency (EPA) or President Obama's Climate Action Plan was regularly dismissed as being ineffective and imprudent. The government was accused of "central planning" the economy as it would restrict energy choices and the usage of cars and appliances. In several text passages, the think tank rejected the implementation of carbon taxes or cap and trade measures as this would generate more costs than benefits - instead, the CTT proposed cutting "carbon subsidies" that would keep gasoline and diesel prices far below market levels.

Within the Economy category, the Economic Investment counterclaim was prevalent. Cato warned against the negative effects of carbon mitigation policies on the economy. These effects were called "economically disastrous" and a "burden" for the American taxpayer because of high costs. However, neither the disadvantages of renewable energy technologies nor the advantages of fossil fuels were invoked frequently in their blog communication. Therefore, this category did not play a major role during the whole period observed. This is a surprising outcome since one would expect a greater dominance of economic factors as this 
CTT can be categorized as libertarian. The categories Technology, Religion/Values, and National Security did not play a major role.

\subsection{Findings for the Heritage Foundation}

For the Heritage Foundation, the growth of the category Science and the stable dominance of Political Ideology as the centre of their argumentation are especially interesting.

In contrast to the Cato Institute, the Heritage Foundation continued to deny that global warming is happening (category Science). In four specific years (2010, 2013-2015), the counterclaim Scientific Uncertainty (Trend) was found in over 10\% of all of the foundation's blog articles, reaching a peak in 2013 with $20.6 \%$. Here, the CTT focused on highlighting the idea that global warming had stopped as of 1997 although $\mathrm{CO}_{2}$ emissions had increased, describing it as a "global warming plateau". This development would indicate that there is no global warming at all. Heritage repeatedly denied that human activity plays an important role. On the contrary, Heritage stated that climate change was predominantly the result of natural causes, as the climate has always changed in the past. Additionally, the impact of carbon dioxide was constantly downplayed by describing it as an "odourless, non-toxic gas" and a non-pollutant. Additionally, the personal integrity of climate scientists was targeted (Scientists' Agenda counterclaim) although this was mainly limited to the years 2010 and 2011 while the "Climategate" controversy was going on.

The category Political Ideology emerged as Heritage's main battlefield over the years analysed. More than $30 \%$ of all deployed counterclaims could be assigned to this category. Here, the Government's Role in Regulating counterclaim was the most prevalent (found in more than $37 \%$ of articles). The main topics were several energy and climate legislation proposals, like the Lieberman-Warner Climate Security Act, the Waxman-Markey bill, or the Clean Power Plan. The think tank predicted that if bureaucratic rule over the economy was extended because of climate change, it would lead to a "power grab" by the EPA. Such "unelected bureaucrats" and environmentalists would want to "micro-manage" and deindustrialize the economy to halt climate change. According to the Heritage Foundation, environmental groups are profiteers who just want to "fill their coffers" by inventing new scare tactics while using the threat of climate change to attack the free market and the capitalist society:

It is an irrefutable truth that many climate change activists are using the climate change issue as a means of attacking free market capitalism. [...]: 'The structural causes of climate change are linked to the current capitalist hegemonic system.' [...] So how is it delusional paranoia to believe that the climate change industry wants to shut down capitalism when the movement plainly states that this is their objective? (Daily Signal, 22 March 2015)

Government was generally deemed as being unsuitable to pick "winners and losers" in the market and therefore should neither grant subsidies in the energy market nor dictate what kind of energy consumers should use. Here, Heritage demands a free market as economic development would be the key to reacting to environmental distress.

The counterclaim most often deployed by Heritage was the Economic Investment counterclaim within the Economics category, which could be found in over half of all its blog articles. The main intention of Heritage was to frame attempts to cut carbon emissions repeatedly as lose-lose scenarios that would result in "economic pain with no environmental gain". Renewables were criticized as being too expensive and inefficient in comparison to fossil fuels, 
unable to drive $\mathrm{CO}_{2}$ emissions down, and responsible for increasing the risk of outages (Economics of Energy counterclaim).

Another prevalent category was Risk, where the Physical Risks of climate change were downplayed (16.3\%) by pointing out that, despite forecasts, several physical catastrophes have not occurred - or have nothing to do with climate change. Thus, hurricanes and tornadoes would not become more frequent; floods and droughts would increase and decrease anyway; current sea level rise would be moderate, and, furthermore, it varies naturally over decades. Riskier, according to Heritage, were the Externalities (this counterclaim was found in $12.8 \%$ of all blog articles) of fighting climate change. The categories Technology, Religion/Values, and National Security did not play a major role.

\section{Discussion}

Previous studies found that CTTs change their counterclaims and that their climate sceptical discourse changed over time. We show that for German and American CTTs, the dominant counterclaims prevail over time. At the same time, we show how the organized climate scepticism movement differs between these two countries. With these insights, our research contributes to the literature on social movement research in the climate change denial context in two main regards.

First, we develop a deeper understanding of organized climate scepticism as a social movement, highlighting the differences between CTTs based in Germany and the USA. As such, our paper responds to calls for continued and in-depth analyses of cross-national comparisons of climate-sceptic claims. As organized attempts to promote climate scepticism are far from over - and will perhaps even intensify with the US planning to leave the Paris Agreement and a resurgent right-wing movement throughout Europe (Milfont et al. 2013; Jylhä et al. 2019) — pro-climate awareness campaigns can utilize our findings to confront the counterclaims used to establish "global warming's non-problematicity" (McCright and Dunlap 2003, p. 354) more effectively. This can include revealing the tactics of climate change deniers to the public (Diethelm and McKee 2009) and trying to debunk typical myths they use (Cook and Lewandowsky 2011). Furthermore, it is essential to produce easy-to-readcontentconsidering that "information that is easy to process is more likely to be accepted as true" (Cook and Lewandowsky 2011, p. 3). This also includes speaking from the local level rather than focusing on the global perspective, which is too abstract. Pro-climate awareness campaigns should also consider the necessity of combining climate change mitigation with positive aspirations supported by the use of emotions and visuals (Futerra Sustainability Communications Ltd. 2005).

Second, our results contribute to a better understanding of how organized climate change denial as a social movement evolves over time and which dominant counterclaims prevail. The arguments used by the CTTs show variances over time but, surprisingly, did not change substantially. This also holds for the time period surrounding the Paris Agreement. This insight seems important to further enable effective and targeted awareness campaigns in response to the efforts of the climate denial movement. Raising awareness is necessary in advance of special events, but it is particularly essential in the long-term to maintain and increase the general level of awareness. This will help to sensitize policy-makers and journalists to the new framing strategies of the climate countermovement so that they can detect and classify 
misinformation about climate change more quickly. In sum, our findings lead to three interesting empirical contributions to the climate change counterframing debate.

\subsection{Dominant counterclaims are CTT-specific}

Arguments about climate science and policy dominate the field for all of the four CTTs but with a different emphasis for each CTT. In terms of EIKE, the category Political Ideology remained stable at nearly $20 \%$ through the entire period observed. For Heritage and Cato, significant movement can be observed during peak periods in 2010 (Cato) and 2012 (Heritage). For the Liberales Institut, prevalence increased year by year. Here, all of the think tanks agreed that climate change is merely used as a means to an end: environmentalists and certain politicians exploit climate change discourse to attack capitalistic society and install their "political utopia" and, somehow, a "global green dictatorship". The Government's Role in Regulating was addressed frequently by three CTTs (Liberales Institut, Heritage, Cato), as it was the most or second most used counterclaim overall.

Climate science has not been the central battlefield for all of the CTTs, yet it still holds importance. Remarkably, EIKE was the only CTT that focused almost entirely on the Science category, with a consistency of around $60 \%$ of all deployed counterclaims. The two US CTTs used science counterclaims differently, with small peaks for both CTTs in 2011 and 2013. The Liberales Institut was the only CTT that noticeably reduced climate science-sceptical arguments in its blog communication over time. All CTTs concentrated primarily on attacking the IPCC and its climate models, in order to present scientific evidence of climate change as wrong or, at the very least, highly doubtful. "This demonstrates that the IPCC is far from being a neutral institution in science [...]" (Liberales Institut, 5 March 2010). This Scientific Uncertainty (Process) counterclaim turned out to be the most important one within the Science category for all CTTs. Scientific consensus was therefore consistently identified as "nonexistent" by all CTTs. Notably, EIKE and the Heritage Foundation denied that the global climate is warming at all and even claimed that the earth is cooling instead. Contrary to this, Cato and Liberales Institut hardly applied the Scientific Uncertainty (Trend) counterclaim despite also recognizing the "pause" in global warming. Cato even explicitly admitted that global warming exists but insisted that the claimed rate of warming is exaggerated and that the earth is instead "lukewarming". On the other hand, CTTs mostly neglected anthropogenic influence by highlighting the harmlessness of carbon dioxide: "The relation between carbon dioxide and the global temperatures is debatable" (Liberales Institut, 20 September 2013). All think tanks claimed that climate sensitivity is much lower than it is thought to be, and natural causes are mainly responsible for the world's changing climate: “[....] paper after paper shows that the equilibrium climate sensitivity - that is, how much global warming will result from a doubling of the atmospheric carbon dioxide concentration - is much lower than most pre-2010 determinations" (Cato Institute, 31 July 2013). This confirms recent findings that a new and important counterclaim has emerged within the CTT countermovement (Boussalis and Coan 2016; Cann and Raymond 2018). In sum, the outright denial of climate change witnessed a remarkable decline in relation to its prevalence in the late 1990s, despite CTTs having kept this strategy alive. Instead, CTTs have primarily focused on creating doubt about the seriousness and credibility of climate science and its institutions, such as the IPCC.

Framing climate change policies as damaging to the economy varied widely from one think tank to another between 2008 and 2016. For the Heritage Foundation, the Economic Investment counterclaim was by far the most important one in its blog communication, with a 
prevalence of 55.7\%: "And the economic pain, no matter how big or small, would all be for no environmental gain [...]" (Heritage Foundation, 22 September 2009). Nonetheless, for the other CTTs, the results were far below the findings of McCright and Dunlap (2000), although the counterclaim remained a key component of their misinformation campaigns. German CTTs deployed this counterclaim in $26.2 \%$ (Liberales Institut) or $12.8 \%$ (EIKE) of their blog articles, while the Cato Institute disseminated it in only $11 \%$ of climate-related articles on its weblog. The think tanks often argued that (energy) costs for the consumer and taxpayers would rise as a consequence of climate mitigation approaches. This strong emphasis on the effects of climate policy on the consumer was also detected by Cann and Raymond (2018). Generally, we do not see fundamental changes with regard to the relevance of the seven categories; however, there are movements in the relative importance of individual counterclaims per CTT. For all four CTTs, the categories Technology, Religion/Values, and National Security did not play a major role at all.

\subsection{No changing relevance of arguments in the aftermath of the Paris Agreement}

The 2015 Paris Agreement is an important step towards addressing climate change. Many supporters of the agreement were hopeful that the extent of the agreement would put sufficient pressure on the participating nations to act upon it rapidly and rigorously. Therefore one could have expected a significant impact on the use of counterclaims by CTTs after COP21, such as further publicly doubting the integrity of recognized climate scientists and questioning the grade of alarmism when it comes to impacts of climate change. Surprisingly, no significant modification has been observed. For both American CTTs, the counterclaims in the Science category show a small rise, whereas this category decreases for the German CTTs. For the Heritage Foundation, a slightly stronger emphasis on the Science category can be illustrated by dominant quotes such as: "Treating climate change as an absolute, unassailable fact, instead of what it is - an unproven, controversial scientific theory [...]" (Heritage Foundation, 4 April 2016). The three CTTs analysed in 2016 vehemently criticize the Paris Agreement, e.g.: "[...] In this manner, the US could be out of both the Paris Agreement and the framework convention as early as Jan. 20, 2018" (Heritage Foundation, 17 November 2016, The Pathway out of Paris); "Far from being toothless, the Paris Agreement is the framework for a multidecade global campaign of political pressure directed chiefly against Republican leaders (...) and the fossil fuel industry” (Cato Institute, 3 March 2016); “(...) the Paris Agreement is far from achieving a reduction of the global $\mathrm{CO}_{2}$-emissions, it is more a blank check allowing China and India to increase their emissions (...)" (EIKE, 28 May 2016). One could have expected a significant increase of policy counterclaims before COP21 in order to influence the negotiations and to stress the negative impact that CTTs feared stronger climate change policy would have on their domestic economies. After the Paris Agreement, one could have expected a slight decline of the policy targeted arguments again, as the direct influencing might not seem to be realistic anymore. In contrast, for the Heritage Foundation, the category Political Ideology shows a significant upward trend after 2015. This certainly can be interpreted as an effort towards the USA resigning the Paris Agreement.

\subsection{US CTTs show greater variability compared to German CTTs}

In general, the two US CTTs present a more diverse picture when looking at the counterclaims used over time. They both use arguments from at least four of the categories (Risk, Political 
Ideology, Science, and Economy), whereas EIKE and the Liberales Institute primarily focus on one or two categories. Additionally, since the 1990s, the US think tanks have incorporated new counterclaims. This underlines how US climate-sceptic CTTs in particular seem to be able to adapt to external influences and effects. They use a wider spectrum of arguments and adapt their framing focuses more readily. One potential explanation we see for this is that the USA functions as a hotbed for climate change deniers, which perfectly prepares the ground for diverse denial campaigns, whereas in Germany, climate change denial attempts have to be persistent and very focused in order to challenge the scientifically established fact that anthropogenic global warming is not a myth.

When it comes to the greater variability of US CTTs, the Heritage Foundation shows remarkable growth in the relevance of the category Science. In addition, the stable dominance of Political Ideology puts a special emphasis on the counterclaim Government's Role in Regulating, stressing that "a far better approach is to simply let the market do its work" (Heritage Foundation, 15 August 2008, Asking McCain, Obama the Right Questions about Social Justice). Despite that, the categories Risk and Economy were also observed and have peaks in 2013 (Economy) and 2014 (Risk). On the whole, their dominant categories have a shifting trend with changing peaks and low points. This can further be detected for the Cato Institute with the focus on the categories Risk, Political Ideology, and Science. Interestingly, these changes are somehow contradictory, e.g. data from 2012 indicates a peak for Political Ideology from the Heritage Foundation, whereas it was an absolute low point for the Cato Institute. Similarly, in 2015, the growing importance of Science for the Heritage Foundation aligns with a low point for Science at Cato.

The German CTTs reveal a different picture: while EIKE focused almost exclusively on Science, the Liberales Institute strengthened the categories of Political Ideology and Economy. In contrast to EIKE, the Science category for the Liberales Institute decreased during the years (with the only peak in 2013).

\section{Conclusion}

The need for rapid action on climate change is immense, yet there is an organized countermovement that aggressively denies anthropogenic global warming. Our analysis focuses on this countermovement. In systematically assessing the blog content of four think tanks in the USA and Germany, we show in detail what kind of climate-sceptic counterclaims were used between 2008 and 2016, how they evolved over time, and which cross-national differences exist. We find that the prevalence of counterclaims used is CTT-specific, with the US CTTs showing a greater variability compared to their German counterparts. Generally, counterclaims regarding climate policy and science dominate the field. Surprisingly, we do not find any evidence that the Paris Agreement changed fundamentally the communication strategy for any of the CTTs, as we do not observe a marked changing relevance of arguments.

In light of the US plans to withdraw from the Paris Agreement and right-wing populist parties gaining strength in Europe, effective awareness campaigns in response to climate scepticism are important. The central challenge for climate policy - as well as for climate science-remains retaining the power of interpretation when it comes to climate change. Implementing effective measures to fight climate change requires public support. The climate-change-denying countermovement is distorting reality and disrupting public support. Thus, providing a good understanding of the counterclaims utilized by this countermovement 
is and will be central to academic research. One avenue for future research in this regard is to examine how counterclaims change in response to actual climatic changes and corresponding societal and economic developments. For example, the consequences of climatic changes have become more and more tangible in some parts of the USA, ranging from water shortages to forest fires. The negative economic implications are obvious. In the meantime, the Fridays for Future movement has brought climate change to a higher level of public awareness. Supposing that broader segments of the public become aware of the severe problems caused by climatic changes, we would presumably also see changes in the use of the counterclaims.

Funding Open Access funding enabled and organized by Projekt DEAL.

Open Access This article is licensed under a Creative Commons Attribution 4.0 International License, which permits use, sharing, adaptation, distribution and reproduction in any medium or format, as long as you give appropriate credit to the original author(s) and the source, provide a link to the Creative Commons licence, and indicate if changes were made. The images or other third party material in this article are included in the article's Creative Commons licence, unless indicated otherwise in a credit line to the material. If material is not included in the article's Creative Commons licence and your intended use is not permitted by statutory regulation or exceeds the permitted use, you will need to obtain permission directly from the copyright holder. To view a copy of this licence, visit http://creativecommons.org/licenses/by/4.0/.

\section{References}

Banerjee SB (2012) A climate for change? Critical reflections on the Durban United Nations climate change conference. Organ Stud 33(12):1761-1786

Begley S (2007) The truth about denial. Newsweek 150(7):20-27 29

Benford RD (1987) Framing activity, meaning, and social movement participation: the nuclear disarmament movement. PhD thesis. Austin

Benford RD (1997) An insider's critique of the social movement framing perspective. Sociol Inq 67(4):409-430

Boussalis C, Coan TG (2016)Text-mining the signals of climate change doubt. Glob Environ Chang 36:89-100

Brulle RJ (2014) Institutionalizing delay: foundation funding and the creation of U.S. climate change countermovement organisations. Clim Chang 122(4):681-694

Brulle RJ, Carmichael J, Jenkins JC (2012) Shifting public opinion on climate change: an empirical assessment of factors influencing concern over climate change in the U.S., 2002-2010. Clim Chang 114(2):169-188

Cann HW (2015) Climate change, still challenged: conservative think tanks and skeptic frames. West Polit Sci Assoc:1-19

Cann HW, Raymond L (2018) Does climate denialism still matter? The prevalence of alternative frames in opposition to climate policy. Environ Polit 27(3):433-454

Cook J, Lewandowsky S (2011) The debunking handbook. University of Queensland, St. Lucia

Diethelm P, McKee M (2009) Denialism: what is it and how should scientists respond? Eur J Pub Health 19(1): 2-4

Dunlap RE (2013) Climate change skepticism and denial. Am Behav Sci 57(6):691-698

Dunlap, R.E. \& McCright, A.M (2010). Climate change denial: sources, actors and strategies, in C. Lever-Tracy (Eds.) Routledge handbook of climate change and society, p. 240-259London/New York: Routledge)

Dunlap RE, McCright AM (2015) Challenging climate change: the denial countermovement. In: Dunlap RE, Brulle RJ (eds) Climate change and society: sociological perspectives. Oxford University Press, New York, pp 300-332

Elsasser SW, Dunlap RE (2013) Leading voices in the denier choir: conservative columnists' dismissal of global warming and denigration of climate science. Am Behav Sci 57(6):754-776

Futerra Sustainability Communications Ltd (2005) The rules of the game: principles of climate change communications. Climate Change Communications Working Group. Available at: http://www.defra.gov.uk/ environment/climatechange/pubs/pdf/ccc-rulesofthegame.pdf

Gamson WA, Modigliani A (1989) Media discourse and public opinion on nuclear power: a constructionist approach. Am J Sociol 95(1):1-37 
Häussler T, Adam S, Schmid-Petri H, Reber U (2017) How political conflict shapes online spaces: a comparison of climate change hyperlink networks in the United States and Germany. Int J Commun 11:3096-3117

Hoffman AJ (2011) Talking past each other? Cultural framing of skeptical and convinced logics in the climate change debate. Org Environ 24(1):3-33

Howe PD, Mildenberger M, Marlon JR, Leiserowitz A (2017) Yale climate opinion maps - U.S. 2016. Available at http://climatecommunication.yale.edu/visualizations-data/ycom-us-2016/?est=happening\&type= value\&geo=county. Accessed 15 September 2019

Jacques PJ, Dunlap RE, Freeman M (2008) The organisation of denial: conservative think tanks and environmental scepticism. Environ Polit 17(3):349-385

Johnston H, Larana E, Gusfield JR (1994) Identities, grievances, and new social movements. In: Larana E, Johnston H, Gusfield JR (eds) New social movements: from ideology to identity. Temple University Press, Philadelphia

Jylhä, K. M., Strimling, P., \& Rydgren, J. (2019). Climate change denial among radical right-wing supporters, (40), 1-16

Kaiser J, Rhomberg M (2016) Questioning the doubt: climate skepticism in German newspaper reporting on COP17. Environ Commun 10(5):556-574

Klandermans B, Staggenborg S (2002) Methods of social movement research. Social movements, protest and contention, 1st edn. University of Minnesota Press

Lefsrud LM, Meyer RE (2012) Science or science fiction? Professionals' discursive construction of climate change. Org Stud 33

Levy D, Kolk A (2002) Strategic responses to global climate change: conflicting pressures on multinationals in the oil industry. Bus Polit 4:275-300

MacKay B, Munro I (2012) Information warfare and new organizational landscapes: an inquiry into the ExxonMobil-Greenpeace dispute over climate change. Organ Stud 33(11):1507-1536

McAdam D (1996) Conceptual origins, current problems, future directions. In: McAdam D, McCarthy JD, Zald MN (eds) Comparative perspectives on social movements. Cambridge University Press, Cambridge, pp 2340

McCarthy JD, Zald MN (2015) Social movement organisations. In: Goodwin J, Jasper JM (eds) The social movements reader: cases and concepts, 3rd edn. Wiley Blackwell, pp 159-174

McCright AM, Dunlap RE (2000) Challenging global warming as a social problem: an analysis of the conservative movement's counter-claims. Soc Probl 47(4):499-522

McCright AM, Dunlap RE (2003) Defeating Kyoto: the conservative Movement's impact on U.S. climate change policy. Soc Probl 50(3):348-373

McCright AM, Charters M, Dentzman K, Dietz T (2016) Examining the effectiveness of climate change frames in the face of a climate change denial counter-frame. Top Cogn Sci 8(1):76-97

Meyer DS, Staggenborg S (1996) Movements, countermovements, and the structure of political opportunity. Am J Sociol 101(6):1628-1660

Milfont TL, Richter I, Sibley CG, Wilson MS, Fischer R (2013) Environmental consequences of the desire to dominate and be superior. Personal Soc Psychol Bull 39(9):1127-1138

Noakes JA, Johnston H (2005) Frames of protest: a road map to perspective. In: Johnston H, Noakes JA (eds) Frames of protest: social movements and the framing perspective. Rowman \& Littlefield Publishers, pp 1-28

Oreskes N, Conway EM (2011) Merchants of doubt: how a handful of scientists obscured the truth on issues from tobacco smoke to global warming, Paperback edn. Bloomsbury Press, New York

Rucht D (1990) Campaigns, skirmishes and battles: anti-nuclear movements in the USA, France and West Germany. Organ Environ 4:193-222

Schmid-Petri H, Arlt D (2016) Constructing an illusion of scientific uncertainty? Framing climate change in German and British print media. Communications 41(3):86

Schmid-Petri H, Adam S, Schmucki I, Häussler T (2017) A changing climate of skepticism: the factors shaping climate change coverage in the US press. Public Underst Sci 26(4):498-513

Shehata A, Hopmann DN (2012) Framing climate change: a study of US and Swedish press coverage of global warming. Journal Stud 13(2):175-192

Steentjes K, Pidgeon N, Poortinga W, Corner A, Arnold A, Böhm G, Tvinnereim E (2017) European perceptions of climate change: topline findings of a survey conducted in four European countries in 2016. Cardiff

Stefanic J, Delgado R (1996) No mercy: how conservative think tanks and foundations changed America's social agenda, 1st edn. Temple University Press

Trumbo C (1996) Constructing climate change: claims and frames in US news coverage of an environmental issue. Public Underst Sci 5(3):269-283

van der Wurff R (2009) Climate change policy of Germany, UK and USA. In: Boersema JJ, Reijnders L (eds) Principles of environmental sciences. Springer, Dordrecht

van Rensburg W (2015) Climate change scepticism: a conceptual re-evaluation. SAGE Open 5(2) 
Zald MN, Useem B (1987) Movement and countermovement interaction: mobilization, tactics and state involvement. In: Zald MN, McCarthy JD (eds) Social movements in an organisational society. Transaction, New Brunswick, pp 247-271

Publisher's note Springer Nature remains neutral with regard to jurisdictional claims in published maps and institutional affiliations. 